\section{Manejo do Paciente Psiquiátrico Grave}

Marsal Sanches, Ricardo Riyoiti Uchida e Sergio Tamai. Editora ROCA. 176p. ISBN: 8572418199

O livro Manejo do Paciente Psiquiátrico Grave versa a respeito dos variados enfoques e intervenções aplicados por uma equipe multidisciplinar a pacientes do Centro de Atenção Integrada a Saúde Mental da Santa Casa de Misericórdia de São Paulo (CAISM), referência em manejo de casos psiquiátricos de elevado grau de complexidade.

Organizado por Marsal Sanches, Ricardo Riyoti Uchida e Sergio Tamai, o livro se divide em duas seções: Aspectos Gerais e Tópicos Especiais. Essas seções são compostas por capítulos elaborados tanto por psiquiatras como por profissionais de psicologia, enfermagem, terapia ocupacional e serviço social do CAISM, o que confere ao texto um interessante formato diversificado em olhares e conceitos, muito congruente e sintonizado ao desenho de uma equipe de saúde mental que se propõe a tratar pacientes psiquiátricos complexos em sua apresentação psicopatológica e manejo.
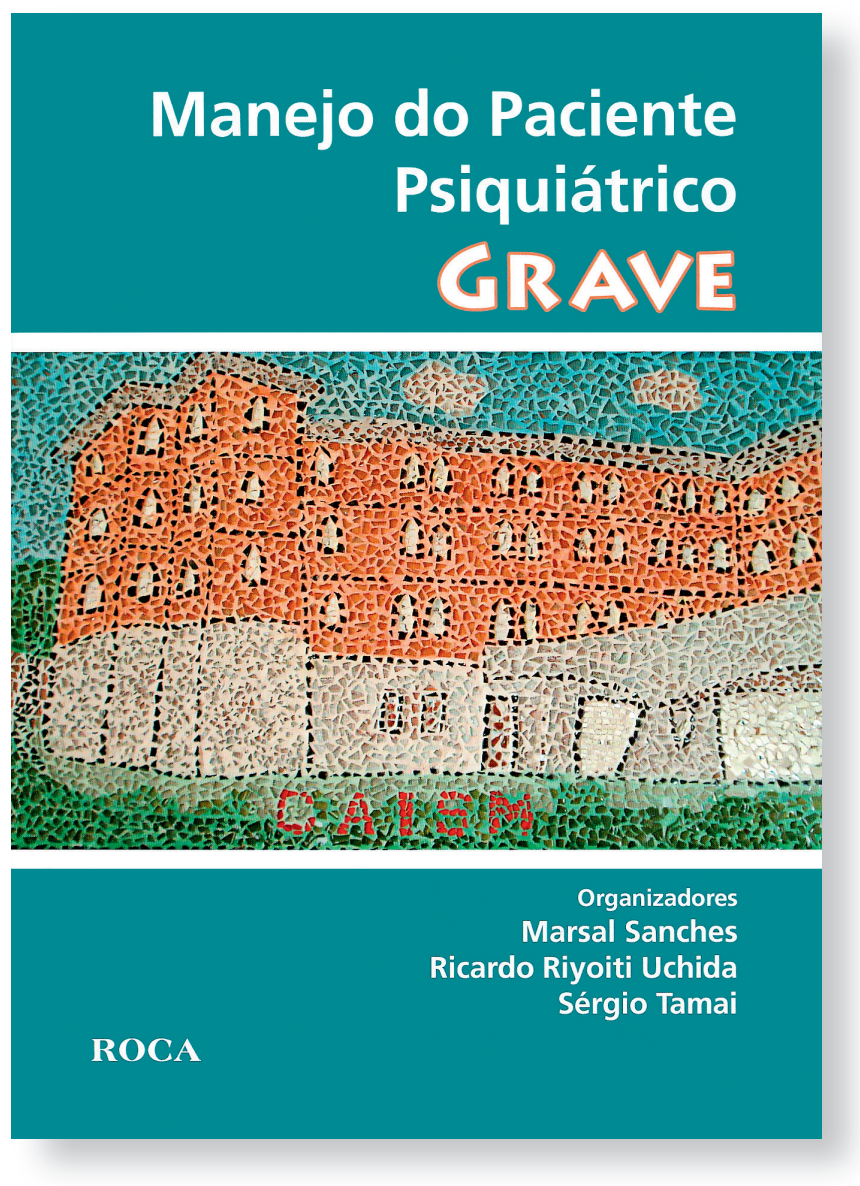

$\mathrm{Na}$ primeira seção, são abordados temas relacionados à conceituação e ao tratamento de pacientes graves tanto em regime de internação como em processo de estabilização e reabilitação sob o enfoque de hospital-dia. Encontramos aqui o referencial teórico-prático, permeado pela importante conceituação de manejo de caso que orienta a atuação multiprofissional do referido serviço, além da fundamentação da abordagem familiar, terapia ocupacional e psicoterapia aplicada a esse perfil de pacientes denominados como portadores de transtorno mental grave (TMG). Finalizando, encontramos um capítulo que foca a intervenção psicofarmacológica - seus riscos, estratégias de abordagem e aderência, relação custo-benefício e variáveis do tratamento.

A seção seguinte é composta por capítulos que possuem uma maior especificidade, como o enfoque de pacientes graves em relação ao uso de substâncias psicoativas, o manejo do paciente idoso portador de TMG e dos pacientes com transtorno de personalidade, incluindo um interessante relato de seu impacto tanto emocional como financeiro às equipes de saúde mental. Não poderia deixar de citar também nessa seção o elucidativo capítulo de emergências psiquiátricas, assunto em relação ao qual o CAISM se apresenta como referência na formação de profissionais de saúde bem como no manejo de casos clínico-psiquiátricos graves em seu pronto socorro; encontramos aqui a abordagem de técnicas de contenção tanto física como farmacológica, bem como o perfil diagnóstico de pacientes que se encontram em estado de emergência psiquiátrica. Finalizando a seção, temos a discussão das comorbidades clínicas, gestação e puerpério, bem como dois capítulos que trazem como tema os aspectos psicodinâmicos e éticos relacionados ao atendimento do paciente grave.

$\mathrm{O}$ livro revela seu valor à medida que nos fornece um referencial teórico e vivencial necessário a abordagem e entendimento do paciente psiquiátrico grave, apresentando como modelo uma instituição que possui larga experiência na abordagem de casos complexos sob o modelo multidisciplinar.

Como profissional que atua em sua prática diária junto à equipe multidisciplinar, focando pacientes em regime de hospital-dia, a grande maioria portadora de TMG, não posso deixar de citar o livro Manejo do Paciente Psiquiátrico Grave como importante referência na literatura especializada a profissionais da área da saúde mental que possuam em seu campo de atuação o interesse por tal perfil de pacientes ou que queiram de forma clara e aprazível enriquecer seu conhecimento a respeito do assunto.

Pedro Altenfelder Silva

Centro de Reabilitação e Hospital-Dia, Instituto de

Psiquiatria, Hospital das Clínicas, Faculdade de Medicina, Universidade de São Paulo (USP), São Paulo, SP, Brasil 